\title{
Retraction of paper: Two visual pigment opsins, one expressed in the dorsal region and another in the dorsal and the ventral regions, of the compound eye of a dragonfly, Sympetrum frequens (Invertebrate Neuroscience, 1, 33-39, 1995)
}

\section{KENTARO ARIKAWA, KOICHI OZAKI, TAKANARI TSUDA, JUNKO KITAMOTO and YUJI MISHINA}

In the above account we reported nucleotide sequences of two novel genes encoding visual pigment opsins of the dragonfly, Sympetrum frequens. However, it appears that the sequences were incorrectly designated as to species: they encode visual pigment opsins of the papilionid butterfly, Papilio xuthus. Therefore, we here retract the paper and express our regret for the confusion.

The error was detected in the course of cloning of butterfly opsins. Sequences identical to the 'dragonfly' opsins were found in the clones isolated from two Papilio retinal cDNA libraries, one of which was constructed after the error in species became evident. Moreover, we repeatedly performed RT-PCR using poly-A-RNA freshly extracted from Sympetrum retinal tissue. The RT-PCR never amplified the fragments of the two reported sequences. We therefore conclude that the sequences ate not those of the Sympetrum opsins, but, most likely, those of the Papilio opsins. The confusion is probably due to contamination of Sympetrum eye poly-A-RNA by that of Papilio, although we cannot specify how and when the contamination was introduced in our experiments. 